\title{
Parâmetros de qualidade de polpas de uva e acerola congeladas
}

\author{
Quality parameters of frozen grape and acerola pulp
}

- Caroline Lanz',

Lucas Nachtigal², Joseana Severo ${ }^{3}$

\section{RESUMO}

$\mathrm{O}$ consumo regular e diversificado de frutas tem sido associado à manutenção da saúde. Contudo, a alta perecibilidade das frutas na pós-colheita é um dos principais problemas do setor frutífero. Devido às limitações da comercialização in natura, a produção de polpas de frutas congeladas torna-se uma excelente alternativa, contribuindo para o aproveitamento integral de frutas excedentes e dispondo derivados das mesmas nas entressafras. Apesar da boa aceitabilidade, falhas no processamento das polpas podem alterar as características nutricionais, sensoriais e organolépticas comprometendo a qualidade do produto. Com isso, o presente estudo analisou os parâmetros de acidez total titulável (ATT), sólidos solúveis totais (SST), contagem de bolores e leveduras e bactérias mesófilas de amostras de polpas de uva e acerola provenientes de uma agroindústria da região Noroeste do Rio Grande do Sul. As polpas foram recebidas no dia do processamento e armazenadas durante 60 dias, a fim de avaliar os parâmetros de qualidade físico-químicos e microbiológicos e comparar com os Padrões de Identidade e Qualidade (PIQ's) da legislação brasileira. As amostras de polpa de uva apresentaram teores de SST inferiores ao mínimo exigido pela legislação após 30 e 60 dias de armazenamento. Já a polpa de acerola apresentou teores de ATT inferiores a legislação no 0 e 30 dia de armazenamento. As análises microbiológicas evidenciaram a necessidade de cuidados com as Boas Práticas de Fabricação (BPF) e a realização da etapa de pasteurização. Os parâmetros físico-químicos demonstraram a importância de utilizar frutos no estádio de maturação adequado para obtenção de polpas de frutas conforme a legislação.

Palavras-chave: Boas práticas de fabricação (BPF). Padrão de Identidade e Qualidade (PIQ). Pasteurização.

1 Instituto Federal Farroupilha - Campus Santo Augusto | caroline.lanz.c|@gmail.com 2 Instituto Federal Farroupilha - Campus Santo Augusto | lucas.nachtigal@gmail.com 3 Instituto Federal Farroupilha - Campus Santo Augusto | joseana.severo@iffarroupilha.edu.br 


\title{
Parâmetros de qualidade de polpas de uva e acerola
} congeladas

\author{
Quality parameters of frozen grape and acerola pulp
}

\section{ABSTRACT}

Frequent and diversified consumption of fruits has been associated with maintaining health. However, one of the main problems presented in the fruit production is the high perishability of fruits in the postharvest. Since this limits its commercialization, the production of frozen fruit pulps becomes an excellent alternative, since it contributes to the integral use of fruits and disposes of them in the off-season. Despite the high acceptability, failures in the processing of pulps may alter the nutritional, sensorial and organoleptic characteristics compromising the quality of the product. Thus, the present study analyzed the parameters of total titratable acidity (TTA), total soluble solids (TSS), mold and yeast counts and mesophilic bacteria from samples of grape pulp and acerola from an agro-industry in the Northwest region of Rio Grande do Sul. The pulps were received on the day of their processing and stored for 60 days in order to evaluate the physicochemical and microbiological parameters, comparing with the norms and Standards of Identity and Quality (PIQ's) of the Brazilian legislation. Grape pulp samples presented lower SST contents than the minimum required by legislation after 30 and 60 days of storage. On the other hand, the pulp of acerola presented levels of ATT lower than the legislation in the 0 and 30 days of storage. Microbiological analyses evidenced the importance of GMP (Good Manufacturing Practice) and the pasteurization. The physicochemical parameters demonstrate the importance of using fruits at the maturation stage appropriate for obtaining fruit pulps according to the legislation.

Keywords: Good manufacturing practices (GMP). Identity and Quality Standard (PIQ). Pasteurization. 


\section{Introdução}

0 patrimônio natural brasileiro é composto por uma ampla extensão territorial, com variados tipos de solos, climas e temperaturas, o que torna possivel o cultivo de diversas espécies frutíferas (CARVALHO, 2017). No entanto, embora haja diversidade e disponibilidade de frutos no mercado brasileiro durante todas as épocas do ano, após a colheita, as frutas mantêm ativos os processos biológicos vitais e, em consequência disso, tornam-se altamente perecíveis, apresentando a comercialização reduzida, especialmente a longas distâncias (CHITARRA; CHITARRA, 2005; CENCI, 2006).

Em vista disso, o processamento da fruta na forma de polpa congelada surgiu como uma excelente alternativa para viabilizar a produção excedente e permitir derivados com as características nutricionais e organolépticas do fruto in natura mesmo nas entressafras (BRUNINI; DURIGAN; OLIVEIRA, 2002; OLIVEIRA et al. 2011).

O Ministério da Agricultura, Pecuária e Abastecimento (MAPA), através da Instrução Normativa № 01 de 07 de janeiro de 2000, define polpa de fruta como sendo o produto não fermentado, não concentrado, não diluído, obtido de frutos polposos, através de processo tecnológico adequado, com um teor mínimo de sólidos totais, proveniente da parte comestível do fruto. Ainda conforme 0 MAPA, não pode apresentar em sua constituição: terra, sujidades, parasitas, fragmentos de insetos e pedaços das partes não comestíveis da fruta e da planta (BRASIL, 2000).

A uva (Vitis sp.) é uma fruta não climatérica, composta por uma ampla variedade de espécies que determinam a composição química da polpa. Em sua constituição, a fruta apresenta teores de ácido tartárico, málico e cítrico que proporcionam o sabor ácido (MARZAROTTO, 2010, p. 363). Além disso, fornece substâncias fenólicas com ações benéficas ao organismo, como flavonóides (catequina, epicatequina, epigalocatequina, quercetina, miricetina e antocianinas) e não-flavonóides (ácidos fenólicos, hidroxibenzóicos e hidroxicinâmicos). Esses compostos bioativos das uvas são responsáveis pelas cores presentes em flores e frutos, co-pigmentos junto das antocianinas, sabor, adstringência, aroma e gosto dos seus derivados (ABE et al., 2007).

A acerola (Malpighia emarginata D.C.), também conhecida como West Indian Cherry (cereja-das-Antilhas), é uma fruta climatérica que possui curta pós-colheita, em média de cinco dias, acidez elevada, devido à presença de ácido ascórbico, e baixo teor de açúcares (MATTA; CABRAL, 2010; OLIVEIRA et al., 2011). Segundo Mendes et al. (2012), o Brasil é considerado o maior produtor, consumidor e exportador mundial de acerola. A valorização dessa pequena fruta deve-se ao potencial nutricional e industrial, sendo caracterizada como uma de baixo valor calórico com um teor considerável de substâncias antioxidantes, como vitamina C, antocianinas (pigmento de coloração vermelha presente na casca), ferro e cálcio, que auxiliam no sistema de defesa do organismo (RITZINGER; RITZINGER, 2011; MERCALI et al., 2011). Possui sabor e aroma agradável, apresentando fácil cultivo e ampla aplicação industrial no desenvolvimento de diversos produtos alimentícios (MERCALI et al., 2011).

A industrialização de polpas visa à transformação da matéria in natura em produtos com características microbiológicas e sensoriais seguras. Entretanto, sem os cuidados de Boas Práticas de Fabricação (BPF) é inevitável que ocorram transformações químicas, bioquímicas e microbiológicas nesses produtos. A qualidade da fruta, assim como da polpa, está relacionada a fatores envolvidos na fase de pré-colheita e de pós-colheita. A microbiota deteriorante da polpa pode ser proveniente de microrganismos presentes naturalmente na fruta, ou então, pode ser introduzida pela ruptura da casca, falta de sanitização da matéria prima, condições higiênicas insatisfatórias dos manipuladores e das instalações industriais que acabam permitindo a proliferação (CABRAL; JÚNIOR FREIRE; MATTA, 2010, p. 203; CENCl, 2006).

As frutas e os derivados são em geral alimentos ácidos, fator que restringe o crescimento da microbiota deterioradora, especialmente dos microrganismos patogênicos. A microbiota normalmente 
presente constitui-se em bolores, leveduras, bactérias lácticas e outros microrganismos ácido tolerantes (SIQUEIRA; BORGES, 1997 apud SANTOS; COELHO; CARREIRO, 2008). A Instrução Normativa No 01 de 07 de janeiro de 2000 do Ministério da Agricultura, Pecuária e Abastecimento (MAPA) estabelece que a características físicas, químicas e organolépticas deverão ser as provenientes do fruto de

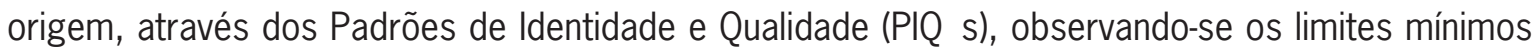
e máximos fixados para cada polpa de fruta. Frente às características microbiológicas, fixa o limite máximo de $5 \times 10^{-3} \mathrm{UFC} / g$ para contagem de bolores e leveduras em polpas de frutas in natura, não estabelecendo nenhum padrão para bactérias mesófilas (BRASIL, 2000).

Dessa forma, o presente trabalho teve como objetivo avaliar as características físico-químicas e microbiológicas de polpas congeladas de uva e acerola comercializadas na região Noroeste do estado do Rio Grande do Sul.

\section{Metodologia}

0 desenvolvimento do estudo foi realizado nos laboratórios de Microbiologia e Bromatologia de Alimentos do Instituto Federal Farroupilha, Campus Santo Augusto, Rio Grande do Sul, durante o período de março a junho de 2018.

Foram coletadas 12 amostras de polpas, sendo seis amostras de acerola e seis de uva de uma única agroindústria da região Noroeste do estado. As acerolas processadas eram provenientes da agricultura familiar e as uvas da cultivar Isabel e Ives da cidade de Antônio Prado-RS. As polpas permaneceram congeladas $\left(-4{ }^{\circ} \mathrm{C} \pm 11^{\circ} \mathrm{C}\right)$ durante 60 dias para a realização das análises físico-químicas no período de 0,30 e 60 dias de armazenamento e as análises microbiológicas no $60^{\circ}$ dia de armazenamento.

Para realização das análises, as amostras foram previamente descongeladas à temperatura ambiente $\left(25^{\circ} \mathrm{C}\right)$, e em seguida foi realizada a caracterização físico-química das polpas de frutas de acordo com os procedimentos descritos pelo Instituto Adolfo Lutz (IAL, 2008) e a microbiológica, seguida pelos procedimentos descritos por Silva et al. (2007).

\section{a. Determinação de Acidez Total Titulável}

A acidez total titulável (ATT) foi determinada pelo método da titulação volumétrica com indicador. De cada amostra, foram retiradas três alíquotas de $5 \mathrm{~g}$ e pesadas em erlenmeyers. Em seguida, foi adicionado $45 \mathrm{~mL}$ de água destilada e três gotas de fenolftaleína alcoólica a $1 \%$. A amostra foi titulada até atingir o ponto de viragem, sob agitação, com uma solução de $\mathrm{NaOH} 0,1 \mathrm{~N}$. Os resultados foram expressos \% de ácido cítrico para a acerola e \% de ácido tartárico para a uva.

\section{b. Determinação de Sólidos Solúveis Totais}

0 teor de sólidos solúveis totais (SST) foi determinado por refratometria, utilizando-se refratômetro de mesa, marca Shimatzu ${ }^{\circledR}$, à temperatura ambiente. Os resultados foram expressos em ${ }^{\circ}$ Brix.

\section{c. Determinação de bolores e leveduras}

A contagem de bolores e leveduras foi determinada a partir do método de plaqueamento direto em superfície das diluições $10^{-1}, 10^{-2}, 10^{-3}$ em meio Ágar Batata Dextrose (BDA) acidificado. Alíquotas de $100 \mu \mathrm{L}$ foram semeadas na superfície dos meios e homogeneizadas com o auxílio de uma alça de Drigalsky. Em seguida, as placas foram incubadas a $25{ }^{\circ} \mathrm{C}$ por três a cinco dias. Os resultados foram expressos pelo número de Unidades Formadoras de Colônia por grama de polpa (UFC/g). 


\section{d. Determinação de bactérias mesófilas}

A contagem de bactérias mesófilas foi determinada pelo método de plaqueamento em profundidade das diluições 10-1, 10-2, 10-3 em meio Plate Count Agar (PCA). Alíquotas de $1000 \mu \mathrm{L}$ foram colocadas sobre a superfície de placas, e em seguida, o meio fundido foi vertido sobre a cultura, homogeneizado-se suavemente com movimentos circulares. Em seguida, as placas foram incubadas em posição invertida a $36^{\circ} \mathrm{C}$ por 48 horas. Os resultados foram expressos pelo número de Unidades Formadoras de Colônia por grama de polpa (UFC/g).

\section{e. Estatística}

As análises foram realizadas em triplicata e as médias obtidas foram utilizadas para calcular 0 desvio padrão e submetidas à ANOVA e ao teste de Fisher a 5\% de significância (XLSTAT, 2016).

\section{Resultados e discussão}

Os resultados das análises de ATT e SST das polpas congeladas ao longo de 60 dias estão apresentados na Quadro 1. Os teores de ATT e SST são parâmetros importantes e relacionados com mudanças químicas que ocorrem durante 0 amadurecimento da fruta in natura (CHITARRA; CHITARRA, 2005), influenciando diretamente no sabor das polpas de frutas.

\section{Quadro 1 - Características físico-químicas de polpa de acerola e uva congelada e armazenada} durante 60 dias

\begin{tabular}{|l|l|l|}
\hline $\begin{array}{l}\text { Tempo de } \\
\text { armazenamento (dias) }\end{array}$ & $\begin{array}{l}\text { Acidez Total } \\
\text { Titulável (\% ácido*) }\end{array}$ & $\begin{array}{l}\text { Sólidos Solúveis } \\
\text { Totais ( }{ }^{\circ} \text { Brix) }\end{array}$ \\
\hline ACEROLA & $0,78 b$ & 8 a \\
\hline 0 & $0,78 b$ & $7,5 b$ \\
\hline 30 & $0,81 a$ & $7,5 b$ \\
\hline 60 & $0,80 a$ & $14 a$ \\
\hline UVA & $0,71 b$ & $13,75 a$ \\
\hline 0 & $0,71 b$ & $13,25 a$ \\
\hline 30 & & \\
\hline 60 &
\end{tabular}

Médias seguidas pelas mesmas letras na linha não apresentam diferença significativa pelo teste de Fisher a 5\%. *Polpa de acerola: \% ácido cítrico; Polpa de uva: \% ácido tartárico

Fonte: elaborada pela autora

Os ácidos orgânicos quantificados na análise de ATT são responsáveis pelo sabor ácido das frutas, sendo variáveis de acordo com a espécie. A acerola em sua maior parte apresenta teores de ácido cítrico, enquanto a uva de ácido tartárico. À medida que esses frutos amadurecem, o conteúdo de ácidos diminui devido à utilização no ciclo de Krebs ou devido à transformação em açúcares durante o processo respiratório (CHITARRA; CHITARRA, 2005). Segundo Gomes et al. (2002), os açúcares solúveis presentes nos frutos na forma combinada são responsáveis pela doçura, sabor e cor atrativa como derivado das antocianinas e pela textura, quando combinados adequadamente a polissacarídeos estruturais. Uma das principais modificações nas características das frutas durante sua maturação é 
o acúmulo de açúcares, principalmente glicose, frutose e sacarose, o qual ocorre simultaneamente com a redução dos ácidos (PROSPERO, 2010).

No tempo 0 e 30, observa-se que a polpa de acerola analisada não apresentava o teor mínimo de ácido cítrico estabelecido pela legislação brasileira que é de 0,8\% (BRASIL, 2000), apresentando teores de $0,78 \%$. No $60^{\circ}$ dia de armazenamento, a polpa apresentava o teor permitido, no entanto abaixo dos teores encontrados por Bueno et al. (2002) e Caldas et al. (2010), 1,4\% e 0,9 a 1,7\% de ácido cítrico, respectivamente, em polpas de acerola.

Os teores de SST da polpa de acerola variaram de $8^{\circ}$ Brix a $7,5^{\circ}$ Brix, diminuindo com o decorrer do tempo de armazenamento, estando de acordo com o mínimo requerido pela legislação de 5,5 ${ }^{\circ}$ Brix (BRASIL, 2000). Matsuura e Rolim (2002) também encontraram teor de $8{ }^{\circ}$ Brix no suco integral de acerola e Paglarini et al. (2011) e relataram teores de 6,25 a 8,10 ${ }^{\circ}$ Brix na polpa. Considerando a baixa acidez e o elevado teor de SST, pode-se supor que os frutos apresentavam-se em estádio de maturação avançado no momento da produção da polpa, uma vez que, a acidez tende a diminuir com o amadurecimento e o teor de SST aumentar.

0 congelamento é um método bastante eficiente na conservação de polpas de frutas, no entanto alguns compostos antioxidantes podem ser degradados durante longos períodos de armazenamento. Oliveira et al. (2011), estudando o comportamento de compostos enzimáticos e não enzimáticos em purês de diferentes clones de acerola congelados durante 150 dias, observaram que os purês de acerola apresentaram uma diminuição dos antioxidantes não enzimáticos e, em geral, um aumento de atividades de enzimas antioxidantes, que podem ser uma conseqüência de um estresse oxidativo devido ao armazenamento a longo prazo sob congelamento temperaturas. No entanto, apesar dessas reduções significativas, os teores de vitamina $C$ encontrados nos purês de acerola congelados ainda foram superiores ao encontrado em frutos como tomate, limão, abacaxi e caqui (OLIVEIRA et al., 2011).

A acidez da polpa de uva, ao contrário da polpa de acerola, apresentou-se em acordo com a legislação em todos os períodos analisados. Houve uma diminuição dos teores de $0,80 \%$ para $0,71 \%$ no decorrer do armazenamento, porém os resultados mostraram-se superiores a 0,41\% de ácido tartárico, porcentagem mínima exigida pela legislação (BRASIL, 2000). Os resultados concordam com Lima et al. (2015) e Dantas et al. (2010) que também relataram teores de ácido tartárico superiores. Diferenças nos teores de ATT das polpas de uva podem ser decorrentes do índice de maturação apresentado no momento da colheita, como também da cultivar destinada para a produção da polpa. Segundo Guerra (2003), as uvas destinadas à elaboração de suco devem apresentar ATT entre 0,5 e $0,9 \mathrm{~g}$ de ácido tartárico por $100 \mathrm{~mL}$, para que o produto final seja de boa qualidade.

Ao decorrer dos dias de congelamento, a polpa de uva reduziu seu teor de sólidos solúveis de $14{ }^{\circ}$ Brix, equivalente ao mínimo exigido, para $13,75^{\circ}$ Brix e $13,25^{\circ}$ Brix, respectivamente, depois de 30 e 60 dias. Verifica-se que a acidez da polpa estava relativamente acima do mínimo exigido e 0 teor de SST abaixo, pressupõe-se, assim, que o estágio de maturação da uva estava incompleto e, portanto, a espécie não apresentava maturação ideal para o processamento.

Constata-se que com o decorrer do período de congelamento, ambas as polpas apresentaram uma pequena redução nos teores de SST, concordando com os resultados observados para SST por Lopes et al. (2005) para polpa de pitanga congelada durante 90 dias. As oscilações nos teores de sólidos solúveis, assim como para acidez, podem ser decorrentes da falta de padronização na maturação dos frutos e na homogeneização da polpa, porém isso dificilmente seria perceptível ao consumidor, uma vez que as diferenças durante o armazenamento foram mínimas. Carvalho et al. (2017) avaliaram polpas de frutas durante 12 meses, relatando que o congelamento é eficiente na manutenção das características físico-química das polpas. Lopes et al. (2008) relataram uma boa retenção de carotenoides, de 86,24\%, após 90 dias de congelamento da polpa de acerola. 
Na Quadro 2, estão apresentados os resultados obtidos na caracterização microbiológica das polpas de uva e acerola após 60 dias de armazenamento. Os resultados referentes à análise de bolores e leveduras para as polpas de uva e acerola apresentaram contagens divergentes aos parâmetros requeridos pela legislação (BRASIL, 2000), cujo valor máximo estabelecido é de $5 \times 10^{3} \mathrm{UFC} / \mathrm{g}$.

Quadro 2 - Contagem de bolores e leveduras e bactérias mesófilas de polpa de acerola e uva congelada e armazenada durante 60 dias

\begin{tabular}{|l|l|l|l|}
\hline Polpa & $\begin{array}{l}\text { Tempo de } \\
\text { armazenamento (dias) }\end{array}$ & $\begin{array}{l}\text { Contagem de bolores e } \\
\text { leveduras (UFC/g) }\end{array}$ & $\begin{array}{l}\text { Contagem de bactérias } \\
\text { aeróbias mesófilas (UFC/g) }\end{array}$ \\
\hline Acerola & 60 & $2,26 \times 10^{3}$ a $1,27 \times 10^{4}$ & $4,06 \times 10^{2}$ a $9,4 \times 10^{2}$ \\
\hline Uva & 60 & $1,22 \times 10^{4}$ a $1,28 \times 10^{4}$ & $2,63 \times 10^{2}$ a $8,6 \times 10^{2}$ \\
\hline
\end{tabular}

Fonte: elaborada pela autora

Contagens acima da legislação também foram relatadas em amostras de polpa de acerola analisadas por Santos e Nascimento (2014), e em 49,02\% das polpas analisadas por Fazio (2006).

Santos, Coelho e Carreiro (2008) encontraram 89,8\% de contaminação por bolores e leveduras em diversas polpas analisadas que variaram de $<10$ até $6,2 \times 10^{4} \mathrm{UFC} / \mathrm{g}$. Tal contaminação foi parcialmente atribuída ao alto teor de carboidratos das matérias-primas, além do caráter ácido. Segundo Franco e Landgraf (2003), baixas contagens de bolores e leveduras são consideradas normais em alimentos congelados. No entanto, contagens elevadas podem configurar aspecto deteriorante, além da rejeição do produto devido ao risco à saúde pública, provocado pela produção de micotoxinas por algumas espécies de bolores.

A ausência de seleção criteriosa da matéria-prima devido ao pequeno porte das frutas, a compra dos frutos por diferentes fornecedores e a falta de sanitização com água clorada antes do despolpamento, podem ter sido fatores que resultaram na contaminação das polpas de acerola analisadas. Já na industrialização da polpa de uva, um dos impasses ainda presente nas pequenas indústrias, e que pode ter influenciado na contaminação, é a utilização de equipamentos de madeira, como a desengaçadeira. Esses equipamentos aderem partículas e dificultam a limpeza efetiva impulsionando a contaminação.

0 estado de higiene do estabelecimento e manipuladores também influencia significativamente na qualidade dos produtos. A correção de tais falhas poderia ser solucionada com a realização criteriosa das BPFs, através de diferentes ações como certificação da qualidade da água utilizada na indústria, rigorosa seleção e sanitização dos frutos, utilização de equipamentos e utensílios feitos de aço inoxidável, realização de limpeza e sanificação periódicas, capacitação dos funcionários em relação às práticas higiênico-sanitárias em todo o setor industrial. No Brasil, a portaria SVS/MS ${ }^{\circ}$ 326/1997 estabelece os requisitos gerais sobre as condições higiênico-sanitárias e de Boas Práticas de Fabricação (BPF) para estabelecimentos produtores/industrializadores de alimentos e a RDC $n^{\circ}$ 275/2002 dispõe sobre o regulamento técnico de procedimentos operacionais padronizados aplicados aos estabelecimentos produtores/industrializadores de alimentos e traz a lista de verificação das BPF em estabelecimentos produtores/industrializadores de alimentos (BRASIL, 1997; BRASIL, 2002).

Outro ponto importante a ser considerado para a obtenção de polpas de frutas de qualidade é a etapa de pasteurização. Uma vez que, essa etapa inibe e/ou elimina o crescimento destes microrganismos evitando contaminações. No entanto, muitas vezes, esse processo é negligenciado em pequenas agroindústrias. Segundo Torrezan et al. (2018), fungos filamentosos e leveduras são ácido tolerantes que se desenvolvem bem em valores de $\mathrm{pH}$ inferiores a 4 e possuem baixa resistência térmica, de forma que em polpas congeladas, a presença poderia ser facilmente evitada facilmente 
com a realização da pasteurização. Lima et al. (2012) observaram contagens inferiores de bactérias aeróbias mesófilas e bolores e leveduras em polpas de acerolas pasteurizadas em comparação a polpas não pasteurizadas analisadas durante 0 armazenamento.

0 crescimento de microrganismos mesófilos foi menor quando comparado ao crescimento de fungos (Tabela 2). $\mathrm{O}$ baixo valor de $\mathrm{pH}$, apresentado por ambas as polpas, pode ter sido um fator limitante para o crescimento de bactérias patogênicas (SANTOS; CARREIRO; COELHO, 2008), mesmo que as condições higiênico-sanitárias tenham sido inadequadas, conforme os resultados de bolores e leveduras pressupõem.

A contagem de microrganismos mesófilos indica o número de bactérias vegetativas e esporuladas presentes no alimento que se desenvolvem à temperatura de 35 a $37^{\circ} \mathrm{C}$. Essa análise pode ser um indicativo da qualidade sanitária dos alimentos, condições da matéria-prima, desinfecção e controle da temperatura durante o processamento industrial e armazenamento. A maior parte das bactérias patogênicas de origem alimentar são mesófilas. Embora não tenha havido alterações nas características organolépticas da polpa, um número elevado de mesófilos à temperatura ambiente pode ser um indicador de condições insalubres de processamento, resultando em condições favoráveis para o desenvolvimento de microrganismos patógenos (FRANCO; LANDGRAF, 2008).

Os resultados encontrados na contagem de microrganismos mesófilos nas polpas de uva e acerola não ultrapassaram 102 UFC/g (Tabela 2), concordando com o relatado com Lima et al. (2012), que também observaram que as contagens de microrganismos mesófilos não ultrapassaram $10^{2} \mathrm{UFC} / \mathrm{g}$ em polpas de acerola pasteurizadas e não pasteurizadas. Segundo BRASIL (1995 apud FEITOSA, et al., 1997), devido à composição rica em ácidos orgânicos, as polpas apresentam valores de pH entre 2,0 e 4,5 e permitem apenas o desenvolvimento de microrganismos deteriorantes, como as bactérias ácido tolerantes. No entanto, ocasionalmente, bactérias patogênicas podem sobreviver por certo período de tempo, tendendo a diminuir as contagens durante 0 armazenamento. Oliveira et al. (2006) encontraram altas contagens de mesófilos em $74 \%$ das amostras de suco de laranja in natura analisados, relatando valores que variaram entre $10^{5}$ e $10^{6} \mathrm{UFC} / \mathrm{mL}$.

Considerando que não há padrões oficiais estabelecidos para polpas de fruta congelada frente a microrganismos mesófilos, fomenta-se que em se tratando de contaminação de risco, os índices seriam baixos para ambas as polpas. Tendo em vista que as amostras apresentaram-se em acordo com a American Public Health Association (APHA, 2001), a qual sugere o limite de $10^{4} \mathrm{UFC} / \mathrm{mL}$ para mesófilos aeróbios. Da mesma forma, nenhuma das amostras apresentou valores acima de $2 \times 10^{4}$ UFC/placa, contagem que seria considerada elevada para microrganismos aeróbios mesófilos, de acordo com Borges et al. (2018), para o processamento da acerola.

\section{Conclusão}

Conclui-se que o estádio de maturação das frutas influencia diretamente na obtenção de polpas de frutas de qualidade e uniformes com os parâmetros físico-químicos exigidos pela legislação. Além disso, apesar de serem alimentos ácidos, cuidados com as BPFs e a realização da etapa de pasteurização das polpas também são fundamentais e devem ser realizadas para garantir a segurança microbiológica do produto.

\section{Referências}

ABE, L. T. et al. Compostos fenólicos e capacidade antioxidante de cultivares de uvas Vitis labrusca L. e Vitis vinifera L: Ciênc. Tecnol. Aliment., Campinas, v.27, n. 2, 2007. Disponivel em: < http:// www.scielo.br/pdf/cta/v27n2/31.pdf>. Acesso em: 09/04/18. 
Borges MF, Oliveira MEB, Lemos, EH, Muniz CR, Assunção GB, Oliveira AM. Condições higiênico-sanitárias durante o processamento e a vida de prateleira de polpas de frutas tropicais. In: Congresso Brasileiro de Ciências e Tecnologia de Alimentos. 18., 2002; Porto Alegre. Anais [...]. Soc Bras Ciênc Tecnol Alim. p. 2088-91.

BORGES, M. F. et al. Condições higiênico-sanitárias durante o processamento e a vida de prateleira de polpas de frutas tropicais. Embrapa Agroindústria Tropical, Fortaleza, 2018. Disponível em: <http://www.ceinfo.cnpat.embrapa.br/arquivos/artigo_1919.pdf>. Acesso em: 09/04/2018.

BRASIL. Ministério da Agricultura e do Abastecimento. Instrução normativa $n^{0} 1$, de 7 de janeiro de 2000. Regulamento técnico geral para fixação dos padrões de identidade e qualidade para polpa de frutas. Brasília, DF: Diário Oficial da União, 2000.

BRASIL. Ministério da Saúde. Secretaria de Vigilância Sanitária. Portaria da SVS/MS n. 326, de 30 de julho de 1997. Regulamento Técnico sobre as condições higiênico-sanitárias e de Boas Práticas de Fabricação para Estabelecimentos Produtores/Industrializadores de Alimentos. Brasília, DF: Diário Oficial da União, 1997.

BRASIL. Ministério da Saúde. Agência Nacional de Vigilância Sanitária. Resolução RDC nº 275, de 21 de outubro de 2002. Dispõe sobre o Regulamento Técnico de Procedimentos Operacionais Padronizados aplicados aos Estabelecimentos Produtores/Industrializadores de Alimentos e a Lista de Verificação das Boas Práticas de Fabricação em Estabelecimentos Produtores/Industrializadores de Alimentos. Brasília, DF/; Diário Oficial da República Federativa do Brasil, 2002.

BRUNINI, M. A.; DURIGAN, J. F.; De OLIVEIRA, A. L. Avaliação das alterações em polpa de manga Tommy-Atkins - congeladas. Revista Brasileira de Fruticultura, Jaboticabal, v. 24, n. 3, 2002. Disponivel em: <http://www.scielo.br/pdf/rbf/v24n3/15103.pdf>. Acesso em: 07/11/18.

BUENO, S. M. et al. Avaliação da qualidade de Polpas de Frutas Congeladas. Revista do Instituto Adolfo Lutz São José do Rio Preto, 2002.

CABRAL, L. M. C.; JÚNIOR FREIRE, M.; MATTA, V. M. Suco de abacaxi. In: VENTURINI FILHO, Waldemar Gastoni (coord.). Bebidas não alcoólicas: ciência e tecnologia. 1. ed. São Paulo: Blücher, 2010. p. 199-208.

CALDAS, Z. T. C. et al. Investigação de qualidade das polpas de frutas congeladas comercializadas nos estados da Paraíba e Rio Grande do Norte. RN. Revista verde de agroecologia e desenvolvimento sustentável, Mossoró, v.5, n. 4, 2010. Disponivel em: <https://www.gvaa.com.br/revista/index. php/RVADS/article/view/397/379>. Acesso em: 08/05/2018.

CARVALHO, C.. Anuário brasileiro da fruticultura 2017. Santa Cruz do Sul, RS: Gazeta Santa Cruz, 2017. Disponível em: <http://www.editoragazeta.com.br/sitewp/wp-content/uploads/2017/03/ PDF-Fruticultura_2017.pdf>. Acesso em: 06/05/18.

CENCI, S. A. Boas práticas de pós-colheita de frutas e hortaliças na agricultura familiar. In: Fenelon do Nascimento Neto (Org.). Recomendações Básicas para a Aplicação das Boas Práticas Agropecuárias e de Fabricação na Agricultura Familiar. 1. ed. Brasília, DF: Embrapa Informação Tec- 
nológica, 2006. Disponível em: <:http://www.ceasa.gov.br/dados/publicacao/pub09.pdf>. Acesso em: 06/05/18.

CHITARRA, M. I.F. CHITARRA, A. B. Pós-colheita de frutas e hortaliças: fisiologia e manuseio. 2. ed. Lavras, MG: Universidade Federal de Lavras, 2005. Disponível em: <http://www.ebah.com.br/ content/ABAAAhVTIAA/livro-pos-colheita-frutas-hortalicas>. Acesso em: 05/06/2018.

DANTAS, R. L. et al. Perfil da qualidade de polpas de fruta comercializadas na cidade de Campina Grande/PB. Revista verde de agroecologia e desenvolvimento sustentável, Mossoró, v. 5, n. 5, 2010. Disponível em: <https://www.gvaa.com.br/revista/index.php/RVADS/article/view/464>. Acesso em: 09/04/2018.

FAZIO, M. L. S. Qualidade microbiológica e ocorrência de leveduras em polpas congeladas de frutas.(Dissertação de Mestrado). Universidade Estadual Paulista. São José do Rio Preto, 2006. Disponivel em: <https://repositorio.unesp.br/bitstream/handle/11449/88391/fazio_mls_me_sjrp. pdf? sequence $=1$ \&isAllowed=y>. Acesso em: 09/04/2018.

FEITOSA, T. et al. Perfil Microbiológico de polpa de frutas produzidas e comercializadas nos estados do Ceará e Rio Grande do Norte. Curitiba, PR: B.CEPPA, 1997. Disponível em: <https:// www.researchgate.net/publication/269732134_PERFIL_MICROBIOLOGICO_DE_POLPA_DE_FRUTAS_PRODUZIDAS_E_COMERCIALIZADAS_NOS_ESTADOS_DO_CEARA_E_RIO_GRANDE_DO_NORTE >. Acesso em: 20/05/2018.

FRANCO, B. D. G. M.; LANDGRAF, M. Microrganismos indicadores. In: Microbiologia dos alimentos. São Paulo, SP: Editora Atheneu, 2008.

FRANCO, B. D. G.; LANDGRAF, M. Microbiologia de alimentos. 2 ed. São Paulo: Editora Atheneu, 2003.

GOMES, P .M. A., FIGUEIRÊDO, R. M. F., QUEIROZ, A. J. M. Caracterização e isotermas de adsorção de umidade da polpa de acerola em pó. Revista Brasileira de Produtos Agroindustriais, Campina Grande, v. 4, n.2, 2002. Disponivel em: <https://www.researchgate.net/publication/276458950_ CARACTERIZACAO_E_ISOTERMAS_DE_ADSORCAO_DE_UMIDADE_DA_POLPA_DE_ACEROLA_EM_PO>. Acesso em: 05/06/2018.

GUERRA, C.C. (Ed.). Uva para processamento: pós-colheita. Embrapa Informação Tecnológica; Bento Gonçalves: Embrapa Uva e Vinho, 2003.

ZENEBON, 0.; PASCUET, N. S.; TIGLEA, P. Instituto Adolfo Lutz: Métodos Físicoquímicos para Análise de Alimentos. Núcleo de Informação e Tecnologia, São Paulo, 2008.

LIMA, R. M. T. et al. Estabilidade química, físico-química e microbiológica de polpas de acerola pasteurizadas e não-pasteurizadas de cultivo orgânico. Ciência Rural, Santa Maria v. 42, n. 2, 2012. Disponível em: <http://www.scielo.br/pdf/cr/v42n2/a3112cr4228.pdf>. Acesso em:01/05/2019.

LIMA, T. L. S, et al. Avaliação da composição físico-química de polpas de frutas comercializadas em cinco cidades do Alto Sertão paraibano. Revista Verde de Agroecologia e Desenvolvimento 
Sustentável, Pombal, v. 10, n. 2,. 2015. Disponível em: <https://www.gvaa.com.br/revista/index. php/RVADS/article/view/3378/2984>. Acesso em: 05/06/2018.

LOPES, A. et al. Estabilidade da polpa de pitanga sob congelamento, Ciênc. Tecnol. Aliment., Campinas,.v.3, n.25, 2005. Acesso em: 01/05/2019. Disponível em: <http://www.scielo.br/pdf/ cta/v25n3/27026.pdf>. Acesso em: 01/05/2019.

MARZAROTTO, V. Suco de uva. In: VENTURINI FILHO, Waldemar Gastoni (coord.). Bebidas não alcoólicas: ciência e tecnologia. São Paulo, SP: Blücher, 2010. p. 359-384.

MATSUURA, F. C. A. U., ROLIM, R. B. Avaliação da adição de suco de acerola em suco de abacaxi visando à produção de um blendcom alto teor de vitamina C. Revista Brasileira de Fruticultura, São Paulo, n. 1, v. 24., 2002. Disponível em: <https://www.researchgate.net/publication/26351119_Avaliacao_da_adicao_de_suco_de_acerola_em_suco_de_abacaxi_visando_a_producao_de_um_blend_ com_alto_teor_de_vitamina_C>. Acesso em: 01/03/2018.

MATTA, V. M.; CABRAL, L. M. C. Suco de acerola. In: VENTURINI FILHO, Waldemar Gastoni (coord.). Bebidas não alcoólicas: ciência e tecnologia. São Paulo: Blücher, 2010. p. 211-217.

MENDES, A. M. S et al. A cultura da acerola. 3. ed. Brasília, DF: Embrapa, rev. amp., 2012. Disponivel em: <https://ainfo.cnptia.embrapa.br/digital/bitstream/item/128278/1/PLANTAR-Acerola-ed03-2012. pdf $>$. Acesso em: 05/06/18.

MERCALI, J. R. S. et al. Physical properties of acerola and blueberry pulps. Journal of Food Engineering. v. 106, p. 283-289, 2011. Disponivel em: <https://www.sciencedirect.com/science/article/pii/ S026087741100255X>. Acesso em: 01/05/2019.

OLIVEIRA, J. C. et al. Características microbiológicas do suco de laranja in natura. Revista Ciência e Tecnologia de Alimentos, Campinas, v. 26, n.2, 2006. Disponível em: <http://www.scielo.br/ $\mathrm{pdf} / \mathrm{cta} / \mathrm{v} 26 \mathrm{n} 2 / 30167 . \mathrm{pdf}>$. Acesso em: 05/04/18.

OLIVEIRA, L. S. et al. The influence of processing and long-term storage on the antioxidant metabolism of acerola (Malpighia emarginata) purée. 2. ed. Brazil: Braz. J. Plant Physiol., 2011. Disponivel em: <http://www.scielo.br/pdf/bjpp/v23n2/a07v23n2.pdf>. Acesso em: 01/05/2019.

PAGLARINI, C. S. et al. Avaliação físico-química de polpas de frutas congeladas comercializadas na região do médio norte matogrossense. 13. ed. Goiânia: Enciclopédio Biosfera, Centro Cientíico Conhecer, 2011. Disponível em: <http://www.conhecer.org.br/enciclop/2011b/ciencias\%20da\%20 saude/avaliacao\%20fisico.pdf>. Acesso em: 05/05/2018.

PROSPERO, E. T. P. Caracterização da fruta do Jacaratia Spinosa e processamento do doce de jaracatiá em calda com avaliação da estabilidade. Dissertaçao (Mestrado em Ciência e Tecnologia de Alimentos). Piracicaba, Universidade de São Paulo, 2010. Disponível em: <http:// www.teses.usp.br/teses/disponiveis/11/11141/tde-20102010-140901/pt-br.php>. Acesso em: 08/05/2018. 
RITZINGER, R.; RITZINGER, C. H. S. P. Cultivo tropical de fruteiras: acerola. Informe Agropecuário, Belo Horizonte, v. 34, n. 264, p. 17-25, 2011. Disponível em: <https://ainfo.cnptia.embrapa.br/ digital/bitstream/item/54086/1/Acerola-RITZINGER-Rogerio.pdf>. Acesso em: 05/05/18.

SANTOS, W. C.; NASCIMENTO, A. R. Caracterização microbiológica de polpas de quatro frutas regionais comercializadas nas feiras de São Luís/MA. São Luís: Cad. Pes., 2014. Disponível em: <http://www.periodicoseletronicos.ufma.br/index.php/cadernosdepesquisa/article/view/2615/2634>. Acesso em: 07/05/18.

SANTOS, C. A. A.; COELHO, A. F. S.; CARREIRO, S. C. Avaliação microbiológica de polpas de frutas congeladas. Ciênc. Tecnol. Aliment.; Campinas, v. 28, n. 4, 2008. Disponivel em: <http://www. scielo.br/pdf/cta/v28n4/a23v28n4.pdf>. Acesso em: 05/06/2018.

SILVA, N. et al. Manual de métodos de análise microbiológica de alimentos. 3. ed. São Paulo: Varela, 2007.

TORREZAN, R. Árvore do conhecimento: tecnologia de alimentos. Rio de Janeiro, RJ: EMBRAPA, 2018. Disponível em: <http://www.agencia.cnptia.embrapa.br/gestor/tecnologia_de_alimentos/ equipe_editorial.html>. Acesso em: 03/08/2018.

XLSTAT. Statistical software \& data analysis add-on for Excel. Addinsoft Inc, USA, 2016. 